\title{
Oral health status of male adolescent smokeless tobacco users in Saudi Arabia
}

D.E. Al Agili' and H.-K. Park ${ }^{2,3}$

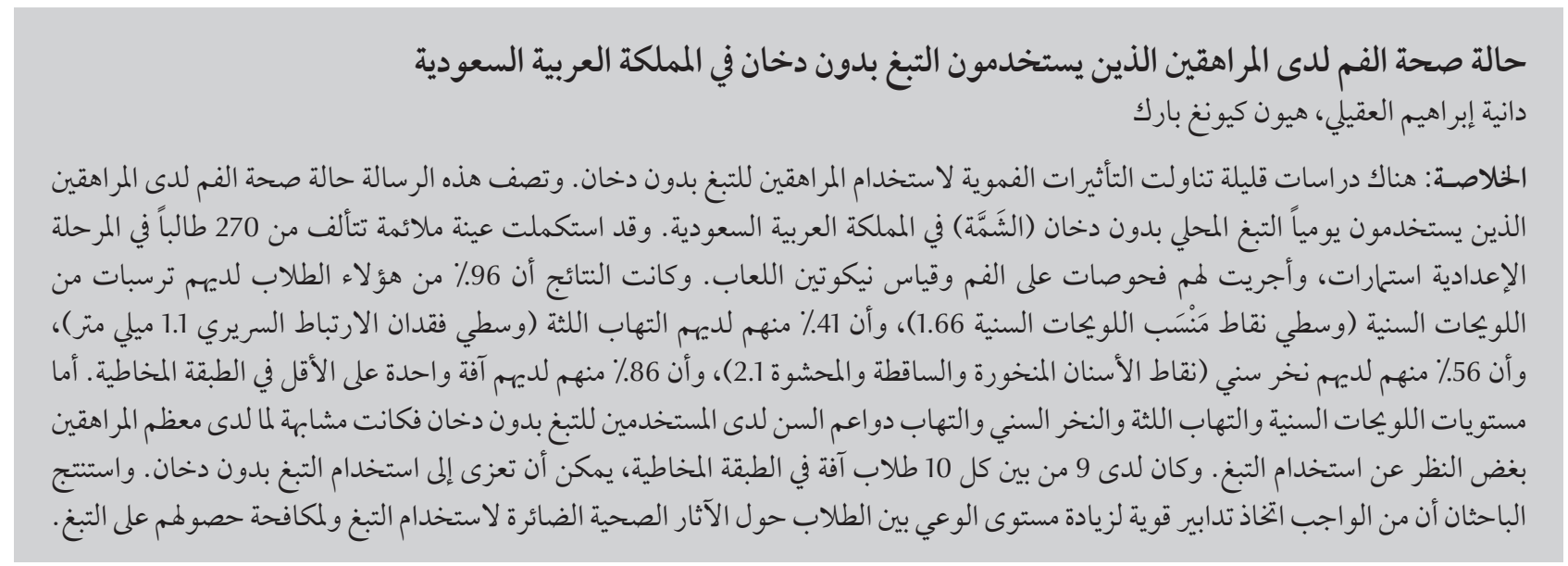

ABSTRACT Few studies have evaluated the oral effects of smokeless tobacco use in adolescents. This study described the oral health status of adolescents who were daily users of local smokeless tobacco (shamma) in Saudi Arabia. A convenience sample of 270 middle-school male students completed a questionnaire and received an oral examination and a saliva cotinine test. Among the students, 96\% had plaque deposits (mean plaque index score 1.66); 41\% had gingivitis (mean clinical attachment loss $1.1 \mathrm{~mm}$ ); $56 \%$ had dental caries (mean decayed, missing, filled teeth score 2.1 ) and $86 \%$ had at least 1 mucosal lesion. The levels of plaque, gingivitis, dental caries and periodontitis among smokeless tobacco users were similar to those of most adolescents regardless of tobacco use. Almost 9/10 students had a mucosal lesion that could be related to smokeless tobacco use. Strong measures should be taken to increase students' awareness of the adverse health effects of tobacco use and to control their access to tobacco.

État de santé bucco-dentaire des adolescents de sexe masculin consommateurs de tabac sans fumée en Arabie saoudite

RÉSUMÉ Peu d'études ont évalué les effets bucco-dentaires de la consommation de tabac sans fumée chez les adolescents. La présente étude décrit l'état de santé bucco-dentaire des adolescents qui consommaient quotidiennement du tabac sans fumée (shamma) en Arabie saoudite. Un échantillon de proximité de 270 élèves du secondaire de sexe masculin a rempli un questionnaire, puis a fait l'objet d'un examen bucco-dentaire et d'une analyse de la concentration salivaire de cotinine. Sur l'ensemble des élèves participants, $96 \%$ présentaient de la plaque dentaire (score moyen de l'indice de plaque 1,66) ; $41 \%$ souffraient de gingivite (perte d'attache clinique moyenne 1,1 mm) ; $56 \%$ avaient des caries dentaires (indice des dents cariées, absentes ou obturées moyen 2,1) et 86 \% étaient atteints d'au moins une lésion de la muqueuse. Les taux de plaque dentaire, de gingivite, de caries et de parodontite chez les consommateurs de tabac sans fumée étaient similaires aux taux observés chez la plupart des adolescents indépendamment de leur consommation de tabac. Près de 9 élèves sur 10 étaient atteints d'une lésion de la muqueuse ayant potentiellement un lien avec la consommation de tabac sans fumée. Des mesures énergiques devraient être prises pour sensibiliser les élèves aux effets indésirables pour la santé de la consommation de tabac et pour contrôler leur accès au tabac

'Community Dentistry Division, Faculty of Dentistry, King Abdulaziz University, Jeddah, Saudi Arabia (Correspondence to D.E. Al Agili: dalagili@) kau.edu.sa). ${ }^{2}$ Graduate School of Public Health, International Cyber University for Health, Yonsei University, Seoul, Korea. ${ }^{3}$ College of Health Sciences and Nursing, University of Phoenix, Phoenix, Arizona, United States of America.

Received: 26/03/12; accepted: 06/05/12 


\section{Introduction}

Tobacco use is a major preventable cause of premature death and also a common risk factor for several general chronic diseases [1]. Although smoking prevention programmes in developed countries have resulted in a decline in the number of smokers over the past 3 decades, smokeless tobacco use has increased, principally due to its heavy consumption by male adolescents and young men $[2,3]$. Smokeless tobacco use causes cancer of the head and neck, oesophagus and pancreas, and many oral diseases such as oral mucosal lesions, leukoplakia and periodontal disease $[4,5]$.

There are 2 major types of smokeless tobacco products: chewing tobacco and snuff. In Saudi Arabia, snuff (shamma) use is common and is largely practised in the southern part of the country and by select populations countrywide [6]. Since the production and import of commercial smokeless tobacco is prohibited in Saudi Arabia, these products are prepared illegally at home without government inspection or monitoring. Smokeless tobacco is readily accessible, cheap and its use by adolescents is easily hidden from parents and teachers [7]. These factors are likely to contribute to its increasing popularity and use among adolescents.

To date, there are no population studies of the prevalence of smokeless tobacco use in Saudi Arabia. In 2010, the authors conducted a study to determine the prevalence of tobacco use among 7 th, 8th and 9th grade schoolchildren in Jeddah, Saudi Arabia. The results indicated that $10 \%$ of these students currently used any tobacco (13\% of boys and $7 \%$ of girls) and smokeless tobacco use was exclusively practised by $2 \%$ of the male students in Jeddah [8]. Studies in other countries have reported substantial occurrence of oral mucosal lesions, a significant correlation between gingival index scores and snuff use and an increased risk of gingival recession among adolescents [9-12]. Nevertheless, data on the association of dental caries and smokeless tobacco use are limited. In general, there is no evidence of tobacco-associated dental caries [9-11]. Offenbacher and Weathers in 1985 reported higher decayed, missing, filled teeth (DMFT) scores among users only if they had gingivitis [11]. Although smokeless tobacco is a well known risk indicator associated with adverse oral health outcomes in adults, few studies have reported statistical differences between adolescent snuff users and non-users. This is likely to be a result of the short exposure time to smokeless tobacco products among adolescents [13-15].

Currently, there are no studies on the oral health status of adolescent smokeless tobacco users in Saudi Arabia. The aim of this study was to describe the oral health status of adolescents who use smokeless tobacco in Saudi Arabia.

\section{Methods}

\section{Study design}

In a cross-sectional study middle-school students completed a self-administered questionnaire and received a comprehensive oral examination and a saliva cotinine test in May 2010.

\section{Subjects}

A convenience sampling method was used to recruit smokeless tobacco users only from public male middle schools in the east and south of Jeddah. These regions are generally recognized as being of low to lower middle socioeconomic class. A total of 15 schools participated in the study. The schools' counsellors were asked to identify and prepare a name list of smokeless tobacco users in their school to enrol in our study. From a total of 391 7th to 9 th grade students who were initially surveyed, $100 \mathrm{stu}-$ dents were not smokeless tobacco users based on their questionnaire responses. Of the 291 who reported smokeless tobacco use, only daily users $(n=270)$ were used in the analysis.

\section{Data collection}

\section{Questionnaire}

The students completed a short questionnaire specially designed for this study before receiving their oral examination. Questions about their dental/oral health, oral health practices, tobacco use and sociodemographic characteristics were included.

\section{Oral clinical examination}

Two trained dentists performed the oral examinations. The students were examined at the schools using portable dental chairs, disposable oral examination kits and head lights for illumination. Williams markings periodontal probe was used to assess periodontal diseases [16]. The oral/dental variables were assessed in the following order.

Oral hygiene status: The oral hygiene status of students was evaluated using the plaque index of Silness and Löe [17]. The presence of plaque deposits was assessed visually on $3 \mathrm{fa}$ cial sites (mesiofacial, mid-facial and distofacial) of 12 selected teeth. These were upper and lower central incisors, upper and lower first premolars, and upper and lower first molars. Missing central incisors were replaced by lateral incisors, missing first premolars were replaced by second premolars and first molars were replaced by second molars. The percentage of students with plaque on any surface of the selected teeth was calculated.

Probing pocket depth (PPD): PPD was measured as the distance from the free gingival margin to the base of the clinical pocket on the 3 facial sites of the 12 selected teeth. The PPD measurement was rounded to the higher whole millimetre [18].

Gingival recession: The distance from the cemento-enamel junction to the free gingival margin was measured on the same sites of the same 12 teeth. It was recorded as a negative value if there were gingival overgrowth and as a positive value if there was a recession. Gingival recession was considered present 
if the free gingival margin was located apical to the cemento-enamel junction. The measurement was rounded to the higher whole millimetre [18].

Clinical attachment loss (CAL): CAL was calculated by adding up the recorded values of the distance from the cemento-enamel junction to free gingival margin and PPD on the 3 sites of the 12 selected teeth [18].

Gingivitis: bleeding on probing (BOP) was recorded following PPD and gingival recession measurements. BOP was scored as positive if bleeding was observed [18].

Dental caries: was scored on all teeth, excluding third molars. The prevalence of dental caries was determined by the presence of any untreated cavities in the user's mouth. In addition, the World Health Organization decayed (D), missing (M), and filled (F) permanent teeth (DMFT) index criteria were used in our oral examination [19]. The student was questioned about the reason for extraction of any missing teeth to confirm caries as the cause of extraction.

Tooth wear: tooth wear was considered positive if there was loss of tooth structure resulting in smooth, hard depressions on the facial surfaces adjacent to the cemento-enamel junction and/ or on occlusal surfaces of all teeth [20].

Tooth stain: tooth stain was recorded as present if it was found on occlusal and/or facial surfaces of all teeth [20].

Oral mucosal lesions (OML): abnormalities of the oral mucosa were categorized into 3 degrees according to Greer and Poulson's criteria [9]: degree 1, a superficial lesion with colour similar to the surrounding mucosa and slight wrinkling; degree 2, a superficial whitish or reddish lesion with moderate wrinkling; and degree 3 , a red or white lesion with obvious thickening and wrinkling [9].

\section{Training and calibration of dental examiners}

Two teams, each consisted of a dental examiner and a recorder, were trained and calibrated to conduct oral examinations. Prior to the study, a didactic instructional session and 9 hours of clinical training were conducted. Twenty (20) middle school male students were invited to the dental school clinics to train the dental examiners in the recordings of the oral indicators. Inter- and intraexaminer reliabilities (percentage agreement) for the recordings of CAL, OML, and dental caries were calculated. The interexaminer reliability for CAL within $1 \mathrm{~mm}$ and OML were $\geq 95 \%$. The interexaminer reliability for dental caries was $\geq 95 \%$. The intraexaminer reliability for CAL within $1 \mathrm{~mm}$ and OML were $\geq 96 \%$. The intraexaminer reliability for dental caries was $\geq 95 \%$.

\section{Cotinine test}

A saliva cotinine test was done for each student after they had completed the questionnaire and before they received the oral examination. NicAlert ${ }^{\mathrm{tx}}$ saliva nicotine test was used for testing. It is a semi-quantitative saliva based test for the determination of in vivo nicotine consumption or exposure. The test was collected and analysed according to the manufacturer's instructions. Each test strip is divided into 6 reactive chromographic (colour change) levels of cotinine detection. Level 1 indicates a cotinine equivalent of $10-30 \mathrm{ng} / \mathrm{mL}$ and level 6 indicates a cotinine equivalent of $2000+\mathrm{ng} / \mathrm{mL}$. Two dental residents were responsible for collecting saliva and administering the test.

\section{Ethical issues}

The project was approved by the ethics committee of the Deanship of Scientific Research at King Abdulaziz University, Jeddah, Saudi Arabia. Furthermore, study clearance was obtained from the Directorate of the Department of Education and the schools observed their own policies for informing parents about the study.

\section{Statistical analysis}

Data were entered in Microsoft Access 2007 and analysed using SAS statistical software, version 9.2. Descriptive statistics in the form of frequencies and means and standard deviation (SD) were computed for participants' demographic data, oral health behaviour and status, and access to dental care and oral health status of smokeless tobacco users related to site of smokeless tobacco use.

Many of the surveyed students used other forms of tobacco such as cigarettes and waterpipe (shisha). The students were classified into 4 groups to evaluate any differences in oral health status between students who used only smokeless tobacco and those who used it in combination with other forms of tobacco. These groups were: smokeless tobacco only, smokeless tobacco and waterpipe, smokeless tobacco and cigarettes, and all types of tobacco. The generalized linear model was applied to analyse the difference in oral health conditions among these groups. Values of $P<0.05$ were considered statistically significant.

To describe the oral health status of smokeless tobacco users related to the site of smokeless tobacco use, we divided the mouth into sextants: sextant A (from upper right second molar to upper right first premolar), sextant B (from upper right cuspid to upper left cuspid), sextant C (from upper left first premolar to upper left second molar), sextant D (from lower left second molar to lower left first premolar), sextant $\mathrm{E}$ (from lower left cuspid to lower right cuspid) and sextant F (from lower left first premolar to lower left second molar). A generalized linear model was used to compare oral health indicators among smokeless tobacco users by sextants. Values of $P<0.05$ were considered statistically significant.

\section{Results}

\section{Characteristics of smokeless tobacco users}

The mean age of the 270 participants was 15.7 (SD 1.5) years, range 13-20 years. All participants were males and 
$82.0 \%$ were of Saudi nationality; $42 \%$ of students were in grade $9,31.8 \%$ in grade 8 , and $26.2 \%$ in grade 7 (Table 1 ). More than half of the students (54.3\%) reported having a low family income $[\leq$ Saudi riyals (SR) 3000], 28.5\% medium income (SR 3001-7000) and 17.2\% high income (> SR 7000). The average daily school allowance was SR 4.7 (range: 0-20). Remarkably, 21.0\% and $32.6 \%$ of students reported that their father and mother respectively were illiterate. Furthermore, $7.2 \%$ and $6.6 \%$ of fathers and mothers respectively had completed high school and $6.7 \%$ and $6 \%$ of fathers and mothers respectively had graduated from college. The majority of students $(87.5 \%)$ reported that both of their parents were alive and $80 \%$ were living with both parents. Most students (73\%) lived with their mother only if their parents were not living together.

\section{Knowledge about and \\ behaviours related to smokeless tobacco use}

ST users were asked about age at starting ST use, knowledge about ST and several behaviours related to their use (Table 2). The mean age at starting ST use was 12.6 (SD 2.4) years. On average, users use 6 chews per day, leave a chew about 11 minutes in the mouth, and chew another in about an hour. Nearly a half (51.3\%) of these students uses smokeless tobacco during the examination period. Interestingly, only $17.8 \%$ knows the content of smokeless tobacco and $3.8 \%$ adds water, pepper, spices or toothpaste to the chew, or wrap it in tissue before use.

\section{Oral health status of smokeless tobacco users and their access to dental care}

Several questions were asked to evaluate students' oral health behaviour and their perceptions of their oral health status and access to dental care (Table 3). A third of respondents (32.6\%) reported having a toothache at the time of the survey. Only 30.5\% brushed their teeth on a daily basis and $16.4 \%$ never

\begin{tabular}{|c|c|c|}
\hline Variable & No. & $\%$ \\
\hline \multicolumn{3}{|l|}{ Student's age (years) ${ }^{a}$} \\
\hline 13 & 14 & 5.2 \\
\hline 14 & 41 & 15.4 \\
\hline 15 & 67 & 25.1 \\
\hline 16 & 67 & 25.1 \\
\hline 17 & 48 & 18.0 \\
\hline 18 & 19 & 7.1 \\
\hline 19 & 8 & 3.0 \\
\hline 20 & 3 & 1.1 \\
\hline \multicolumn{3}{|l|}{ Student's nationality ${ }^{a}$} \\
\hline Saudi & 219 & 82.0 \\
\hline Non-Saudi & 48 & 18.0 \\
\hline \multicolumn{3}{|l|}{ Student's grade } \\
\hline 7 & 70 & 26.2 \\
\hline 8 & 85 & 31.8 \\
\hline 9 & 112 & 42.0 \\
\hline \multicolumn{3}{|c|}{ Student's daily allowance (SR) } \\
\hline $0-2$ & 38 & 14.2 \\
\hline $3-4$ & 77 & 28.7 \\
\hline $5-7$ & 125 & 46.6 \\
\hline $8-10$ & 26 & 9.7 \\
\hline$>10$ & 2 & 0.8 \\
\hline \multicolumn{3}{|l|}{ School region } \\
\hline East & 166 & 61.5 \\
\hline South & 104 & 38.5 \\
\hline \multicolumn{3}{|l|}{ Father's education $^{a}$} \\
\hline Illiterate & 56 & 22.3 \\
\hline$<$ High school & 153 & 61.0 \\
\hline High school degree & 18 & 7.2 \\
\hline > High school & 24 & 9.6 \\
\hline \multicolumn{3}{|l|}{ Mother's education ${ }^{a}$} \\
\hline Illiterate & 88 & 34.2 \\
\hline$<$ High school & 136 & 53.0 \\
\hline High school degree & 17 & 6.6 \\
\hline > High school & 16 & 6.2 \\
\hline
\end{tabular}

${ }^{a}$ Missing values are not included.

brushed. Moreover, at least one-third (33.1\%) had visited the dentist in the past year and $26.7 \%$ had never been to a dentist. Among those who had visited a dentist, most (40.6\%) went for toothache or tooth decay (38.1\%).

Analysis of the oral clinical examination findings showed that $96 \%$ of these students had plaque deposits on their teeth and the mean plaque index score was 1.66 (SD 0.51). Although 41\% presented with gingivitis, none of the students showed signs of periodontal disease. The mean CAL was 1.1 (SD $0.37) \mathrm{mm}, 1 \%$ had gingival recession and the mean pocket depths ranged from 1.1-3.4 $\mathrm{mm}$. The percentages of smokeless tobacco users with $<2 \mathrm{~mm}$, $2-3 \mathrm{~mm}$ and $>3 \mathrm{~mm}$ pocket depths 


\begin{tabular}{|c|c|c|c|}
\hline \multirow[t]{2}{*}{ Variable } & \multicolumn{3}{|c|}{ Value } \\
\hline & Mean (SD) & Median & Range \\
\hline Age at starting ST use (years) & $12.6(2.4)$ & 13 & $6-20$ \\
\hline No. of ST chews/day & $5.6(4.8)$ & 4 & $1-30$ \\
\hline No. of min. ST chew left in mouth & $11.0(10.9)$ & 10 & $1-60$ \\
\hline \multirow[t]{2}{*}{ No. of min. between chews } & 445 (2817) & 60 & $2-432$ \\
\hline & No. & $\%$ & \\
\hline Use ST while sleeping & 18 & 6.4 & \\
\hline Use ST as soon as you wake up & 94 & 33.5 & \\
\hline Use ST if sick & 43 & 15.4 & \\
\hline Use ST while having mouth sores & 45 & 16.0 & \\
\hline Use ST during examination period & 142 & 51.3 & \\
\hline Know the content of ST & 60 & 17.8 & \\
\hline Add other substances to ST chew & 10 & 3.8 & \\
\hline
\end{tabular}

$S D=$ standard deviation

were $50.7 \%, 48.5 \%$ and $0.7 \%$ respectively. The prevalence of dental caries was $56 \%$ and the mean DMFT score was 2.1 (SD 2.77). The decay (\% D) component of the DMFT represented the highest (80\%) proportion of the index score (range $72 \%-89 \%$ ). None of the students showed any tooth wear and up to $5 \%$ showed some tooth stains related to smokeless tobacco use.

A simple linear regression analysis of the relationship between selected oral variables showed significant associations between frequency of tooth brushing and gingival recession $(t=2.31 ; P<$ $0.05)$ and frequency of tooth brushing and gingivitis $(t=2.04 ; P<0.05)$.

Multivariate analyses of mean pocket depth and CAL with variables such as age, parents' education, income, brushing frequency, dental visits and plaque index scores found that only mean plaque index score was statistically significantly associated with both pocket depth $(P=0.02)$ and $\operatorname{CAL}(P=$ $0.03)$ (Table 4).

An interesting finding of this study was that $85.9 \%$ of smokeless tobacco users had at least $1 \mathrm{OML}$. Among users with at least 1 lesion $(n=232), 45.5 \%$ had OMLs of degree $1,32.0 \%$ had degree 2 and $22.5 \%$ degree 3 lesions.
The majority $(87.0 \%)$ of all OMLs $(n=$ 316) were located in the upper anterior area where smokeless tobacco is habitually placed. There were no significant associations found between these lesions and oral health variables such as brushing frequency and dental visits. Among demographic factors, the region of schools was statistically significantly associated with $\mathrm{OML}(\mathrm{OR}=0.85 ; 95 \%$ CI: 0.73-0.98). Schools in the eastern region of Jeddah were more likely to have users with lesions compared to students from the southern region (OR $=0.85 ; 95 \%$ CI: $0.7-0.9$ ). The level of salivary cotinine was also significantly associated with the presence of smokeless tobacco-associated OML (OR = 1.5; 95\% CI: 1.1-1.8).

The distribution of the studied oral health conditions among the 4 groups of tobacco users are presented in Table 5 . The students who used only smokeless tobacco had the lowest mean plaque scores 1.58 (SD 0.54) and those who used smokeless tobacco and smoked waterpipes had the highest scores 1.71 (SD 0.47), although no statistical significant difference was observed. Gingivitis was highest among students who used smokeless tobacco in combination with cigarette smoking (52\%) and was lowest among students who used all types of tobacco $(31 \%)(P<0.05)$. The prevalence of dental caries was highest among the smokeless tobacco only users (65\%) compared with the other 3 groups (49\%, 53\% and 58\%); however, the difference was not statistically significant. The mean salivary cotinine scores did not show any significant differences among students, ranging from 2.47 (SD 1.32) among users of both cigarettes and smokeless tobacco to 2.69 (SD 1.24) among users of all types of tobacco (score $2=30-100 \mathrm{ng} / \mathrm{mL}$ cotinine; score $3=100-200 \mathrm{ng} / \mathrm{mL}$ cotinine).

\section{Sextant-specific oral health status of smokeless tobacco users}

To describe the oral health status of smokeless tobacco users in relation to site of smokeless tobacco use, we divided the mouth into sextants. We used a general linear model for comparing oral health indicators among smokeless tobacco users by sextants. Table 6 presents the means and frequencies of oral health conditions for each sextant. The majority of students (95\%) placed the smokeless tobacco dip in the vestibule of the upper anterior region, whereas only $30 \%$ placed the dip in the vestibule of the 


\begin{tabular}{|c|c|c|}
\hline Variable & No. & $\%$ \\
\hline \multicolumn{3}{|l|}{ Pain in teeth } \\
\hline Yes & 88 & 32.6 \\
\hline No & 182 & 67.4 \\
\hline \multicolumn{3}{|l|}{ Pain in gums } \\
\hline Yes & 36 & 13.3 \\
\hline No & 234 & 86.7 \\
\hline \multicolumn{3}{|l|}{ Bad breath } \\
\hline Yes & 62 & 23.0 \\
\hline No & 208 & 77.0 \\
\hline \multicolumn{3}{|l|}{ Frequency of brushing teet $h^{a}$} \\
\hline Daily & 82 & 30.5 \\
\hline Every other day & 69 & 25.7 \\
\hline 2-3 times a week & 51 & 19.0 \\
\hline Weekly & 23 & 8.6 \\
\hline Do not brush & 44 & 16.4 \\
\hline \multicolumn{3}{|l|}{ Past dental visit } \\
\hline$<6$ months & 68 & 25.2 \\
\hline 6 months to $<1$ year & 20 & 7.4 \\
\hline 1 to $<3$ years & 22 & 8.2 \\
\hline$>3$ years & 18 & 6.7 \\
\hline Never been to a dentist & 72 & 26.7 \\
\hline Don't know /don't remember & 70 & 25.9 \\
\hline \multicolumn{3}{|l|}{ Reason for visit ${ }^{a}$} \\
\hline Check-up/cleaning & 27 & 14.1 \\
\hline Toothache & 54 & 38.1 \\
\hline Tooth decay & 78 & 40.6 \\
\hline Treatment & 16 & 8.3 \\
\hline Other & 17 & 8.9 \\
\hline
\end{tabular}

${ }^{a}$ Missing values are not included.

lower anterior region. In general, the posterior sextants showed more CAL and PPD compared with the anterior sextants ( $B$ and $E$ ).

Furthermore, the mean CAL and PPD were higher for the upper posterior sextants compared with the lower posterior sextants; however, no statistical significant differences were found between groups. The upper anterior sextant (sextant B) had the lowest percentage of $\mathrm{BOP}(33 \%)$ and a low plaque index score (1.47), whereas the area of sextant $\mathrm{A}$ presented with the highest percentage of BOP (47\%; $P<0.05)$ and a high plaque index score (1.81). The mean DMFT was lowest (0.04) in the lower anterior region and highest in the lower posterior teeth.

\section{Discussion}

The age of our sample was somewhat higher than expected for usual middle school students. This may be attributed to the convenience sampling method which targeted only tobacco users in these schools. Data from the $2009 \mathrm{Na}$ tional Youth Risk Behavior Survey in the United Sates of America showed a negative association between tobacco use and academic achievement after controlling for sex, race/ethnicity and grade level. Students with higher grades (As and Bs) were less likely to use tobacco than students with lower grader (Ds and Fs) [21].

Information gathered about the knowledge of student-users and their behaviours related to smokeless tobacco use are generally useful for designing and implementing comprehensive tobacco prevention programs. The findings, especially those related to the content of smokeless tobacco, should prompt research in the field of chemistry and toxicology of local smokeless tobacco (shamma) varieties used in Saudi Arabia. Limited research has been conducted into this subject [22].

Previous studies of adult tobacco users showed significant associations between periodontal disease and tobacco use $[14,23]$. We were not able to find any associations between periodontitis and smokeless tobacco use in this sample of young students. In the few studies conducted among adolescents, Greer and Poulson reported that 25\% of smokeless tobacco users had gingival recession at the placement site [9]. Furthermore, Offenbacher and Weathers reported significant gingival recession among adolescent smokeless tobacco users with coexisting gingivitis only [11]. Most of the smokeless tobacco users in the previous studies habitually placed the smokeless tobacco dips in the mandibular anterior region and the majority of the OML were in the mandibular arch, affecting tissues adjacent to the mandibular anterior teeth $[9,24]$. The observed recession may be due to the narrower width of attached gingiva in this area compared with that in the maxilla and/or the use of vigorous tooth brushing to remove the stains and smell associated with smokeless tobacco use. In our study, gingival recession and gingivitis in smokeless tobacco users were both significantly associated with frequency of tooth brushing, and $95 \%$ of users used the upper anterior vestibule 


\begin{tabular}{|c|c|c|c|c|c|}
\hline \multirow[t]{2}{*}{ Variable } & \multirow[t]{2}{*}{ df } & \multicolumn{2}{|c|}{ Mean pocket depth ${ }^{\mathrm{a}}$} & \multicolumn{2}{|c|}{ Mean $\mathrm{CAL}^{\mathrm{b}}$} \\
\hline & & $\begin{array}{l}\text { Parameter estimate } \\
\text { (SE) }\end{array}$ & $t$-value & $\begin{array}{l}\text { Parameter estimate } \\
\text { (SE) }\end{array}$ & $t$-value \\
\hline Intercept & 1 & $1.04(0.32)$ & 3.3 & $2.29(0.31)$ & 7.46 \\
\hline Age & 1 & $-0.01(0.02)$ & -0.55 & $-0.03(0.02)$ & -1.6 \\
\hline Family income & 1 & $-0.01(0.02)$ & -0.33 & $-0.00(0.02)$ & -0.12 \\
\hline Father's education & 1 & $-0.01(0.01)$ & -0.99 & $-0.02(0.01)$ & -1.29 \\
\hline Mother's education & 1 & $0.019(0.02)$ & 1.24 & $0.02(0.01)$ & 1.26 \\
\hline Frequency of brushing teeth & 1 & $0.02(0.02)$ & 0.77 & $0.01(0.02)$ & 0.3 \\
\hline Plaque score & 1 & $0.12(0.06)$ & $2.22^{*}$ & $0.12(0.05)$ & $2.29 *$ \\
\hline Time since last visit to dentist & 1 & $0.00(0.02)$ & 0.1 & $0.00(0.02)$ & 0.14 \\
\hline Cotinine level & 1 & $-0.03(0.02)$ & -1.41 & $-0.02(0.02)$ & -1.08 \\
\hline
\end{tabular}

${ }^{a} R^{2}=0.08 ;{ }^{b} R^{2}=0.07$.

${ }^{*} P<0.05$.

$d f=$ degrees of freedom; $S E=$ standard error.

for dipping. Regardless of location of smokeless tobacco dipping, severe periodontal disease is more likely to occur after long-term smokeless tobacco use [23].

Surprisingly, the dental caries prevalence $(56 \%)$ and severity (mean DMFT 2.1) were lower in our sample than in previously reported studies of middle-school students in Saudi Arabia [25-29]. Our findings may be explained by the wide variations in dental caries prevalence $(59 \%-80 \%)$ and severity (DMFT 1.81-4.70), in the permanent teeth of these children relative to the varied fluoride concentration in the water countrywide [30]. Another reason for the observed lower dental caries prevalence may be related to smokeless tobacco use [31]. The accelerated salivary flow in heavy smokeless tobacco users provides physical cleansing and mild buffering actions which inhibit the aggregation of cariogenic bacteria [31]. In addition, smokeless tobacco products are highly alkaline and many contain fluoride

\begin{tabular}{|c|c|c|c|c|}
\hline Oral/dental condition & $\begin{array}{c}\text { Smokeless tobacco } \\
\text { only } \\
(n=170)\end{array}$ & $\begin{array}{c}\text { Waterpipe } \& \\
\text { smokeless tobacco } \\
(n=19)\end{array}$ & $\begin{array}{c}\text { Cigarettes \& } \\
\text { smokeless tobacco } \\
(n=45)\end{array}$ & $\begin{array}{c}\text { All types of } \\
\text { tobacco } \\
(n=36)\end{array}$ \\
\hline Mean (SD) plaque score & $1.58(0.54)$ & $1.71(0.47)$ & $1.66(0.42)$ & $1.69(0.47)$ \\
\hline Plaque (\%) & 92 & 94 & 99 & 99 \\
\hline Mean (SD) pocket depth $(\mathrm{mm})$ & $2.03(0.39)$ & $1.94(0.31)$ & $2.07(0.37)$ & $1.93(0.33)$ \\
\hline Probing pocket depth 2 mm (\%) & 52 & 47 & 53 & 33 \\
\hline Probing pocket depth $3 \mathrm{~mm}$ (\%) & 1 & 0 & 2 & 0 \\
\hline Gingival inflammation (\%) & 39 & 41 & 52 & 31 \\
\hline Gingival recession (mm) & 1 & 2 & 1 & 1 \\
\hline Mean (SD) clinical attachment loss (mm) & $1.06(0.38)$ & $1.03(0.37)$ & $1.13(0.38)$ & $0.98(0.36)$ \\
\hline Dental caries (\%) & 65 & 53 & 49 & 58 \\
\hline Mean (SD) DMFT score & $2.18(2.48)$ & $1.84(2.95)$ & $2.44(4.17)$ & $1.36(1.48)$ \\
\hline D teeth (\%) & 86 & 89 & 74 & 72 \\
\hline M teeth (\%) & 9 & 8 & 25 & 6 \\
\hline F teeth (\%) & 5 & 3 & 1 & 22 \\
\hline Tooth stain (\%) & 4 & 5 & 2 & 3 \\
\hline Tooth wear (\%) & 0 & 0 & 0 & 0 \\
\hline Oral mucosal lesions (\%) & 88 & 95 & 87 & 72 \\
\hline Mean (SD) cotinine score ${ }^{a}$ & $2.62(1.29)$ & $2.53(1.17)$ & $2.47(1.32)$ & $2.69(1.24)$ \\
\hline
\end{tabular}

${ }^{a}$ Score $2=30-100 \mathrm{ng} / \mathrm{mL}$ cotinine; score $3=100-200 \mathrm{ng} / \mathrm{mL}$ cotinine.

$S D=$ standard deviation $;=$ decayed, $M=$ missing,$F=$ filled . 


\begin{tabular}{|c|c|c|c|c|c|c|}
\hline \multirow[t]{2}{*}{ Variable } & \multicolumn{6}{|c|}{ Sextant $^{\mathrm{c}}$} \\
\hline & A & B & C & D & $\mathbf{E}$ & $\mathbf{F}$ \\
\hline Tobacco dipping site ${ }^{\mathrm{a}, \mathrm{b}}(\%)$ & 5 & 95 & $5^{*}$ & $8^{*}$ & $30^{* *}$ & $6^{* * *}$ \\
\hline Mean plaque score & 1.81 & 1.47 & 1.88 & 1.53 & 1.45 & 1.53 \\
\hline Mean pocket depth $(\mathrm{mm})$ & 2.24 & 1.78 & 2.23 & 2.06 & 1.74 & 2.03 \\
\hline Mean clinical attachment loss (mm) & 1.25 & 0.87 & 1.24 & 1.05 & 0.89 & 1.02 \\
\hline Mean gingival recession $(\mathrm{mm})$ & $0.01^{*}$ & 0 & $0.01^{*}$ & 0 & 0.03 & 0 \\
\hline Bleeding on probing (\%) & $47^{*}$ & 33 & 44 & 37 & 39 & 41 \\
\hline Mean DMFT score & 0.34 & 0.39 & 0.39 & 0.47 & 0.04 & 0.46 \\
\hline D teeth (\%) & 83 & 93 & 86 & 70 & 100 & $80^{*}$ \\
\hline M teeth (\%) & 9 & 2 & 5 & 20 & 0 & 10 \\
\hline F teeth (\%) & 8 & $5^{*}$ & $9^{*}$ & $10^{*}$ & 0 & $10^{* *}$ \\
\hline Oral mucosal lesions ${ }^{\mathrm{b}}(\%)$ & 2 & 96 & 4 & 2 & 12 & 2 \\
\hline
\end{tabular}

a Site of use of smokeless tobacco.

${ }^{b}$ Totals more than $100 \%$ because some students use more than 1 site for dipping and have more than 7 lesion in the same sextant.

'Sextants A (from upper right second molar to upper right first premolar), B (from upper right cuspid to upper left cuspid), C (from upper left first premolar to upper left second molar), D (from lower left second molar to lower left first premolar), E (from lower left cuspid to lower right cuspid) and $F$ (from lower left first premolar to lower left second molar).

${ }^{*} P<0.05 ;{ }^{*} P<0.01 ;{ }^{* *} P<0.001$

$D=$ decayed,$M=$ missing, $F=$ filled.

in levels ranging from 0.9 to $2.0 \mathrm{ppm}$, which directly inhibit or slow caries development [31].

A disturbing finding of this study was the high prevalence of OML ( $86 \%$ ) at the site of smokeless tobacco placement. This is much higher than the reported prevalences of $50 \%-70 \%$ in other studies $[14,32,33]$. These lesions are reversible if users quit smokeless tobacco use early in life. However, with long-term, frequent use the lesions are considered precursors of oral cancer. Malignant transformation of leukoplakia from all causes ranges from $3 \%-5 \%$ [7]. In Saudi Arabia, oral cancer is the third most common malignancy in males and the fourth in females [34]. Moreover, the highest percentage (35\%) of oral cancer cases referred to King Faisal Specialist Hospital and Research Center in Saudi Arabia comes from Jizan in the south of the country, where smokeless tobacco use is a common practice [6]. The growing number of adolescent smokeless tobacco users and the $\leq 50 \%$ survival rates of oral cancer make this low rate of malignant transformation a considerable concern $[7,34]$.
One limitation of this study was the selection of 12 teeth to evaluate the periodontal disease among adolescents. This may have underestimated sitespecific periodontal disease. However, previous studies showed that the local effect of smokeless tobacco use may extend to several teeth [20]. Another limitation was the cross-sectional design of the study which made it hard to establish a temporal sequence between smokeless tobacco use and oral diseases/conditions.

\section{Conclusion}

Tobacco impacts the general and oral health of its consumers. Although we were not able to find statistical associations between caries or periodontal disease and smokeless tobacco use, the high prevalence of OML in this sample of young people is alarming. Nine out of 10 students had an OML which could be related to smokeless tobacco use. Therefore, it is urgent to develop comprehensive tobacco prevention programmes especially including elementary schoolchildren in Saudi
Arabia. Furthermore, the results of our study strongly emphasize the pressing need of the government to develop effective polices and to reinforce current policies and regulations affecting access of children to tobacco.

\section{Acknowledgements}

The authors would like to extend their thanks to the Directorate of the Education Department for supporting the study and facilitating access to and cooperation of the schools' administrations. We are also grateful to the dental interns who conducted the oral examinations and questionnaire administration; the principals, teachers, and staff of all participating schools for their support and cooperation; and the students for cooperating with the study.

Funding: This work was supported by the Deanship of Scientific Research, King Abdulaziz University, Jeddah (1431/254/130).

Competing interests: None declared. 


\section{References}

1. Petersen PE. Tobacco and oral health-the role of the World Health Organization. Oral Health and Preventive Dentistry, 2003, 1:309-315.

2. Hellquist $\mathrm{L}$ et al. Tobacco use in relation to socioeconomic factors and dental care habits among Swedish individuals 15-70 years of age, 1983-2003. International Journal of Dental Hygiene, 2009, 7:62-70

3. Reducing tobacco use: a report of the Surgeon General. Atlanta, Georgia, Centers for Disease Control and Prevention, 2000.

4. Henningfield JE, Fant RV, Tomar SL. Smokeless tobacco: an addicting drug. Advances in Dental Research, 1997, 11:330-335.

5. Measures and determinants of smokeless tobacco use, prevention, and cessation (RO1). Request for applications (RFA) number RFACA-08-024. National Institutes of Health, Office of Extramural Research [online] (http://grants.nih.gov/grants/guide/rfafiles/RFA-CA-08-024.html, accessed 4 April 2013).

6. Allard WF, DeVol EB, Te OB. Smokeless tobacco (shamma) and oral cancer in Saudi Arabia. Community Dentistry and Oral Epidemiology, 1999, 27:398-405.

7. Johnson GK, Squier CA. Smokeless tobacco use by youth: a health concern. Pediatric Dentistry, 1993, 15:169-174.

8. Al Agili DE, Park HK. The prevalence and determinants of tobacco use among adolescents in Saudi Arabia. Journal of School Health, 2012, 82:131-138.

9. Greer RO Jr, Poulson TC. Oral tissue alterations associated with the use of smokeless tobacco by teenagers. Part I. Clinical findings. Oral Surgery, Oral Medicine, and Oral Pathology, 1983, 56:275-284.

10. Modeer T, Lavstedt S, Ahlund C. Relation between tobacco consumption and oral health in Swedish schoolchildren. Acta Odontologica Scandinavica, 1980, 38:223-227.

11. Offenbacher S, Weathers DR. Effects of smokeless tobacco on the periodontal, mucosal and caries status of adolescent males. Journal of Oral Pathology, 1985, 14:169-181.

12. Montén U, Wennström JL, Ramberg P. Periodontal conditions in male adolescents using smokeless tobacco (moist snuff). Journal of Clinical Periodontology, 2006, 33:863-868.

13. Poulson TC, Lindenmuth JE, Greer RO Jr. A comparison of the use of smokeless tobacco in rural and urban teenagers. $C A$ : $a$ Cancer Journal for Clinicians, 1984, 34:248-261.

14. Fisher MA, Taylor GW, Tilashalski KR. Smokeless tobacco and severe active periodontal disease, NHANES III. Journal of Dental Research, 2005, 84:705-710.

15. Bergström J. Tobacco smoking and risk for periodontal disease. Journal of Clinical Periodontology, 2003, 30:107-113.

16. Williams CHM. Some newer periodontal findings of practical importance to the general practitioner. Journal of the Canadian Dental Association, 1936, 2:333-340.

17. Löe H, Silness J. Periodontal Disease in Pregnancy. I. Prevalence and severity. Acta Odontologica Scandinavica, 1963, 21:533-551.
18. Page RC, Eke PI. Case definitions for use in population-based surveillance of periodontitis. Journal of Periodontology, 2007, 78(Suppl.):1387-1399.

19. Oral health surveys-basic methods, 4th ed. Geneva: World Health Organisation, 1997.

20. Robertson PB, Walsh MM, Greene JC. Oral effects of smokeless tobacco use by professional baseball players. Advances in Dental Research, 1997, 11:307-312.

21. National Youth Risk Behavior Survey. Centers for Disease Control and Prevention [online] (http://www.cdc.gov/HealthyYouth, accessed 4 April 2013)

22. Idris AM et al. The Swedish snus and the Sudanese toombak: are they different? Oral Oncolology, 1998, 34:558-566.

23. Bouquot J, Schroeder K. Oral effects of tobacco abuse. Journal of the American Dental Institute for Continuing Education, 1992, 43:3-17.

24. Robertson PB, Walsh MM, Greene JC. Oral effects of smokeless tobacco use by professional baseball players. Advances in Dental Research, 1997, 11:307-312.

25. Al-Khateeb TL et al. Dental caries in children residing in communities in Saudi Arabia with differing levels of natural fluoride in the drinking water. Community Dental Health, 1990, 7:165-171

26. Al-Khateeb TL, Al-Marsafi AI, O'Mullane DM. Caries prevalence and treatment need amongst children in an Arabian community. Community Dentistry and Oral Epidemiology, 1991, 19:277-280.

27. Al Dosari AM et al. Caries prevalence and its relation to water fluoride levels among schoolchildren in Central Province of Saudi Arabia. International Dental Journal, 2004, 54:424-428.

28. Al-Sadhan SA. Dental caries prevalence among 12-14 year-old schoolchildren in Riyadh: a 14 year follow-up study of the Oral Health Survey of Saudi Arabia, Phase I. Saudi Dental Journal, 2006, 18:2-7.

29. Farsi N. Dental caries in relation to salivary factors in Saudi population groups. Journal of Contemporary Dental Practice, 2008, 9:16-23.

30. AlDosari AM, Akpata ES, Khan N. Associations among dental caries experience, fluorosis, and fluoride exposure from drinking water sources in Saudi Arabia. Journal of Public Health Dentistry, 2010, 70:220-226.

31. Christen AG. The case against smokeless tobacco: five facts for the health professional to consider. Journal of the American Dental Association, 1980, 101:464-469.

32. Johnson GK, Slach NA. Impact of tobacco use on periodontal status. Journal of Dental Education, 2001, 65:313-321.

33. Salem G, Juhl R, Schiødt T. Oral malignant and premalignant changes in 'shammah'-users from the Gizan region, Saudi Arabia. Acta Odontologica Scandinavica, 1984, 42:41-45.

34. Al-Balawi SA, Nwoku AL. Management of oral cancer in a tertiary care hospital. Saudi Medical Journal, 2002, 23:156-159. 